\title{
Breakfast skipping is associated with cyberbullying and school bullying victimization. A school-based cross-sectional study
}

\section{Hugues Sampasa-Kanyinga, Paul Roumeliotis, Claire V. Farrow and Yuanfeng F. Shia}

\section{Introduction}

Breakfast skipping has become increasingly widespread amongst children and adolescents (Siega-Riz et al, 1998, Storey et al, 2009, Vereecken et al, 2009 and Woodruff et al, 2008), and population-based research data are required to provide a clearer understanding of the possible underlying factors that contribute to and perpetuate breakfast skipping in children and adolescents. A body of research has shown that breakfast skipping in adolescents is associated with various health-risk behaviours, such as smoking, frequent alcohol consumption, marijuana use, infrequent exercise and behavioural disinhibition (Isralowitz, Trostler, 1996 and Keski-Rahkonen et al, 2003). Studies also reported associations of breakfast skipping with socio-economic status (SES), family structure, and the development of overweight and obesity (Levin et al, 2012, Niemeier et al, 2006, O'Dea, Caputi, 2001, Rampersaud et al, 2005, Timlin et al, 2008 and Vereecken et al, 2009). Breakfast skipping has also been reported as a possible indicator of disordered eating (Rampersaud et al., 2005), both sub-clinically (Melve \& Baerheim, 1994) and clinically (Fernandez-Aranda et al., 2007).

Body weight and body image concerns are not the only reasons students skip breakfast. While not being offered breakfast may be a reason for not eating breakfast in younger children, a body of research has reported a variety of other reasons amongst adolescents. In addition to dieting in order to lose weight, Shaw (1998) has reported in a follow-up telephone survey that common reasons given for skipping breakfast were lack of time and lack of appetite in the morning. This supports the need to investigate other determinants as they may offer new insights into how to prevent or reduce breakfast skipping. One such determinant is the experience of bullying. Children and adolescents spend a large amount of their time with friends and peers and many children experience instances of bullying or victimization during their childhood years (Guerra, Williams, \& Sadek, 2011). According to Coping Theory, adolescents engage in high risk behaviours to cope with increased negative effects, which may result from such victimization (Lazarus, 1993), one such behaviour may include breakfast skipping.

Bullying is usually defined as aggression that is intentionally carried out by one or more individuals and repeatedly targeted towards a person who cannot easily defend him or herself (Olweus, 1993). School bullying (bullying on school property) is a major public health concern. Despite the efforts of schools to prevent or stop bullying, bullying is still highly prevalent worldwide (Perren et al, 2010 and Schneider et al, 2012). Beyond the school property, a new form of bullying has rapidly emerged with the advent of technology. Cyberbullying is defined as the use of email, cell phones, text messages, and Internet sites to threaten, harass, embarrass, or socially exclude (Hinduja \& Patchin, 2009). Like school bullying, cyberbullying has also been associated with mental health problems. Several negative consequences have been identified amongst victims of cyberbullying, including increased anxiety and emotional distress (Juvonen, Gross, 2008 and Ybarra et al, 2006), feelings of loneliness, insecurity and humiliation (Breguet, 2007). Victims of cyberbullying may also suffer from low self-esteem, frustration and sadness, and serious distress, including major depression, self-harm, and suicide (Hay, Meldrum, 2010, Patchin, Hinduja, 2010 and Schneider et al, 2012).

Previous research has mostly focused on the association between bullying and eating disorders, or unhealthy eating psychopathology (Farrow, Fox, 2011, Kaltiala-Heino et al, 2000 and Libbey et al, 2008). To the best of our knowledge, there have been no previous reports of a specific association between breakfast skipping and bullying victimization. The objective of this study was to begin to explore the prevalence and associations between cyberbullying and school bullying victimization with breakfast skipping. By doing so we seek to gain a better understanding of the links that may exist between these public health issues. Using a large and diverse sample of Canadian middle and high 
school students, we sought to establish whether the experience of bullying may impact upon breakfast skipping and to further evaluate whether bullying victimization might impact mental health (depression), and in turn lead to breakfast skipping. Indeed, bullying victimization is deemed to increase children's depressive symptoms (Hawker, Boulton, 2000, Perren et al, 2010 and Schneider et al, 2012), and depression is often related to eating behaviour (Frost, Goolkasian, Ely, \& Blanchard, 1982), particularly breakfast skipping (Lien, 2007). We therefore sought to establish whether elevated levels of depression might be the means through which bullying may impact upon breakfast intake. Understanding how bullying impacts upon nutritional behaviour will allow for more targeted interventions to help protect children who are subjected to bullying. It was hypothesized that cyberbullying and school bullying victimization would predict a higher likelihood of breakfast skipping and that depression would mediate these relationships.

\section{Methods}

This study incorporates data from the Eastern Ontario (Canada) 2011 Youth Risk Behaviour Survey (YRBS), a regional school-based survey conducted by the Eastern Ontario Health Unit (EOHU) between November 2010 and March 2011. The EOHU has been monitoring youth health-risk behaviour in the population of this region for several years with the YRBS. The survey was modelled after the Centers for Disease Control's (CDC) YRBS which monitors healthrisk behaviours that contribute to death and disability amongst youths and adults (Centers for Disease Control and Prevention, 2009). The study protocol was reviewed for ethical compliance by the Queen's University Health Sciences and Affiliated Teaching Hospitals Research Ethics Board.

\section{Participants}

Youths in grades 7-12 (11- to 20-year-olds) were the target population of the survey. All school boards were invited to join in the survey, and all schools within the boards that accepted the invitation were eligible for participation. Written consent forms from school principals and parents were verified prior to administering survey questionnaires.

For each school that participated, a list of classes taking place during a certain time of the day was generated. The time period selected varied by school and staff schedule. A random sample of two classes from each grade was selected in each school, unless only one grade was available for the administration of the survey to all students who provided consent. In this way, all students in grades 7-12 had the same opportunity to be selected for participation and were not at risk of being selected to participate twice. The only exception was that students who had spare periods during the selected time slots were not eligible for participation. In the event of teacher refusal to participate $(N=1)$, a second class for that grade was selected from the same time period. Students in selected classes were eligible to participate voluntarily and anonymously. A School Liaison person (Public Health Nurse or Health Educator/Promoter) remained in the classroom while students completed the survey to address any questionnaire-related issues. If students did not understand a question, the Liaison person would re-read the question without leading them in any particular direction. Otherwise, students were asked to complete the questionnaires in silence so that they could not confer with each other. Students who did not participate were given another activity to do. The school response rate was $62 \%$, the student response rate was $68 \%$, and the overall response rate was $42 \%(62 \% \times 68 \%)$. The total sample consisted of 3509 students aged $11-20$, with $54.9 \%$ being girls.

\section{Measures}

The frequency of eating breakfast was measured with the following question: "How many times a week do you usually eat breakfast?" (Never or almost never, one to two times per week, three to four times per week, five or more times per week, every day) (Berkey et al, 2003 and Lien, 2007). Experience of school bullying victimization was measured with the following question: "During the past 12 months, have you ever been bullied or threatened by someone while at school?" (Yes or no). Cyberbullying victimization was measured with the following question: "During the past 12 months, have you ever experienced cyberbullying, that is, being bullied by email, text messaging, instant messaging, social networking or another website?" (Yes or no). 
Depression was assessed by the question: "During the past 12 months, did you ever feel so sad or hopeless almost every day for 2 weeks or more in a row that you stopped doing some usual activities?" (Yes or no). Body weight perception was measured with the item: "How would you describe your current weight?" (Very underweight, underweight, about the right weight, overweight, and very overweight). Tobacco and alcohol use were measured by the following questions: "Have you ever smoked a whole cigarette?" (Yes or no) and "Have you ever had at least one drink of alcohol, other than a few sips?" (Yes or no). Socio-economic status (SES) was measured by assessing the educational levels of fathers and mothers using the following items: "How far did your father go in school? (graduated university, attended university, graduated college, attended college, graduated high school, attended high school, did not attended high school, I don't know, no father) and "How far did your mother go in school? (Graduated university, attended university, graduated college, attended college, graduated high school, attended high school, did not attended high school, I don't know, no mother) (Centre for Addiction and Mental Health, 2009).

\section{Statistical analyses}

Statistical analyses were conducted on individuals with no missing values for any of the variables studied. As a result, of the 3509 students, 3035 (86.5\% of the sample) were included in the analyses. With-and-without analyses showed that excluded missing data from the analyses did not have a significant impact on the results. All data were analysed with STATA (version 12.0, Stata Corp., College Station, Texas) using the svy commands to take account of the complex sampling design of the survey. Body weight perception variables were collapsed into three categories including underweight, about the right weight, and overweight due to the small number of students who reported extreme weight perceptions (i.e., very underweight or very overweight). Breakfast eating frequency was categorized in the following three groups: eat breakfast every day, eat breakfast three times or more per week (often breakfast skipping) and eat breakfast two times or less per week (frequent breakfast skipping) ( Lien, 2007). SES variables were each collapsed into five categories including attended university, attended college, attended high school, did not attended high school, and I don't know. Basic descriptive statistics of selected characteristics stratified by breakfast eating habits were calculated. To determine whether boys and girls could be combined into one analysis; gender-byschool bullying, gender-by-cyberbullying, and gender-by-both forms of bullying victimization interactions were assessed. There were no significant gender interactions. As a result, all analyses were combined for gender in order to maximize statistical power. Multinomial logistic regression analyses were performed to investigate the relationships between cyberbullying, school bullying, and both forms of bullying victimization (explanatory variables) and breakfast skipping categories (outcome variable), using those who ate breakfast everyday as the comparison group. Analyses were adjusted for confounding variables including grade, gender, weight perception, tobacco and alcohol use, and maternal and paternal education levels. Unadjusted as well as adjusted relative risk ratio (RR) and 95\% confidence intervals $(\mathrm{Cl})$ are reported. Statistical significance was set at $\mathrm{p}<.05$.

To examine the mediating role of depression on the association of bullying victimization with breakfast skipping, we followed the Baron and Kenny approach (Baron \& Kenny, 1986) using both binary and multinomial logistic regression analyses controlling for grade, gender, SES, weight perception, and tobacco and alcohol use. Using this approach, mediation is evident if the following four criteria are met: (1) the independent variable (bullying victimization) is associated with the outcome (breakfast skipping); (2) the independent variable is associated with the hypothesized mediator (depression); (3) the mediator is associated with the outcome, controlling for the independent variable, and (4) association between bullying victimization and breakfast skipping is reduced to non-significance (full mediation) or attenuated (partial mediation) when controlling for depression. The Sobel test was used to statistically evaluate whether indirect mediation was significant (Sobel, 1982).

\section{Results}

\section{Sample characteristics}

More than half (55.4\%) of the participants in the study were girls. Overall, students who were in lower grades were oversampled and there were significant differences between boys and girls in the distribution of grade. For example, while $25.6 \%$ and $21.9 \%$ of boys and girls respectively were in grade $7,12.8 \%$ and $15.4 \%$ of boys and girls respectively 
were in grade 12 . Therefore, gender was controlled for in further analyses. Overall, $24.6 \%$ of participants considered themselves overweight, and the distribution of body weight perception significantly varied between genders. Girls were more likely to perceive themselves as overweight, whereas boys were more likely to consider themselves underweight (Table 1). Approximately three quarter of fathers and mothers of the participants had attended a least high school (73.6\% and $77.2 \%$, respectively).

Table 1. Sample characteristics.

\begin{tabular}{|c|c|c|c|}
\hline Total & $3035(100)$ & $1354(44.6)$ & $1681(55.4)$ \\
\hline \multicolumn{4}{|l|}{ Age } \\
\hline Mean age (SD) & $14.3(1.8)$ & $14.2(1.8)$ & $14.3(1.8)$ \\
\hline \multicolumn{4}{|l|}{ Grade*** $^{* * *}$} \\
\hline Grade 7 & $715(23.6)$ & $347(25.6)$ & 368 (21.9) \\
\hline Grade 8 & $630(20.7)$ & $271(21.4)$ & $359(20.8)$ \\
\hline Grade 9 & $446(14.7)$ & 199 (14.7) & $247(14.7)$ \\
\hline Grade 10 & $438(14.4)$ & $197(14.5)$ & $241(14.3)$ \\
\hline Grade 11 & $373(12.3)$ & $167(12.3)$ & $206(12.3)$ \\
\hline Grade 12 & $433(14.3)$ & $173(12.8)$ & $260(15.4)$ \\
\hline Tobacco use ${ }^{a}$ & $490(16.1)$ & $213(15.7)$ & $277(16.5)$ \\
\hline Alcohol use $\mathrm{e}^{\mathrm{a}}$ & $1681(55.4)$ & $775(57.2)$ & 906 (53.9) \\
\hline \multicolumn{4}{|l|}{ Body weight perception* } \\
\hline Underweight & $402(13.2)$ & $209(15.4)$ & $193(11.5)$ \\
\hline About the right weight & $1886(62.1)$ & $864(63.8)$ & $1022(60.8)$ \\
\hline Overweight & $747(24.6)$ & $281(20.8)$ & $466(27.7)$ \\
\hline \multicolumn{4}{|l|}{ Educational level of father* } \\
\hline Attended university & $672(22.1)$ & $338(25.0)$ & 334 (19.9) \\
\hline Attended college & $760(25.0)$ & $348(25.7)$ & $412(24.5)$ \\
\hline Attended high school & $804(26.5)$ & $329(24.3)$ & $475(28.3)$ \\
\hline Did not attended high school & $38(1.3)$ & $16(1.2)$ & $22(1.3)$ \\
\hline I don't know & $761(25.1)$ & $323(23.8)$ & $438(26.0)$ \\
\hline \multicolumn{4}{|l|}{ Educational level of mother } \\
\hline Attended university & $924(30.4)$ & $440(32.5)$ & $484(28.8)$ \\
\hline Attended college & $780(25.7)$ & $354(26.1)$ & $426(25.3)$ \\
\hline Attended high school & $640(21.1)$ & $244(18.0)$ & $396(23.6)$ \\
\hline Did not attended high school & $21(.7)$ & $11(.8)$ & $10(.6)$ \\
\hline I don't know & $670(22.1)$ & 305 (22.5) & $365(21.7)$ \\
\hline Depression** & $753(25.0)$ & $234(17.5)$ & $519(31.1)$ \\
\hline
\end{tabular}

Data are shown as No. (\%) unless otherwise specified.

$p$ value of difference between boys and girls: ${ }^{*} p<.05 ;{ }^{* *} p<.01 ; * * p<.001$.

a Values indicate the percentage of respondents answering "Yes" for each item. "No" responses are not shown.

\section{Prevalence of breakfast skipping}

Approximately half of the participants (50.4\%) reported not eating breakfast on a regular basis: $26.3 \%$ and $24.1 \%$ reported often (usually eat breakfast three times or more per week) and frequent (usually eat breakfast twice a week or less) breakfast skipping behaviour, respectively. Girls were more likely to frequently skip breakfast than boys ( $27.8 \%$ vs. $19.6 \% ; p<.01)$. Breakfast skipping behaviour also showed an increase with student's grade, as older grade-level students skipped breakfast more frequently than their younger peers ( Table 2). Participants who perceived themselves as overweight were more likely to frequently skip breakfast than those who perceived themselves as about the right weight or underweight ( Table 2). Children of parents with lower levels of education (father and/or mother did not attend high school) were more likely to frequently skip breakfast than those of more educated parents. 


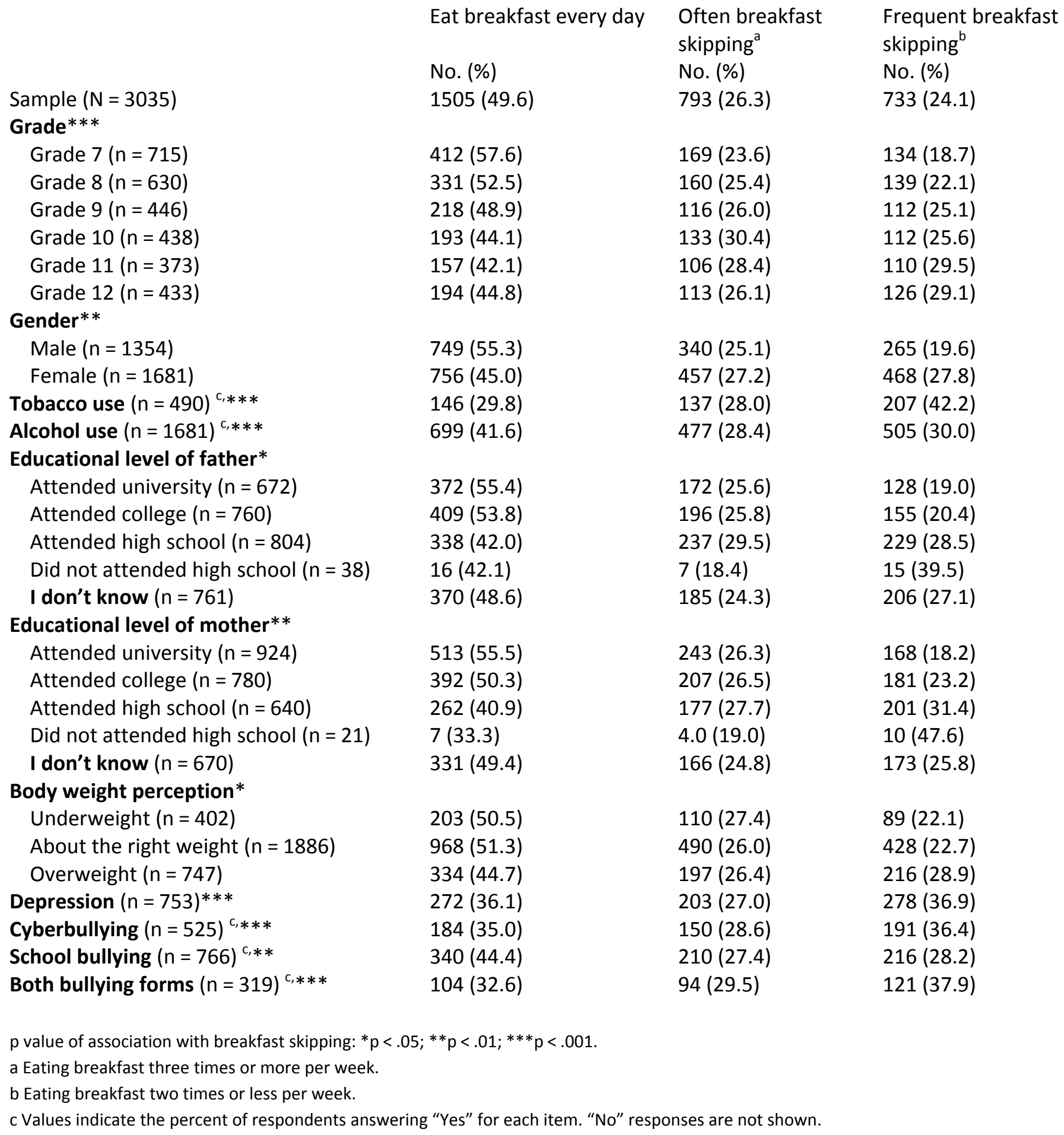

\section{Prevalence of bullying victimization}

Figure 1 displays the prevalence of bullying victimization by gender. A total of $17.3 \%$ of students were victims of cyberbullying and $25.2 \%$ were victims of school bullying, while $10.5 \%$ were victims of both cyberbullying and school bullying. The majority of victims of cyberbullying (60.8\%) were also victims of school bullying; $41.6 \%$ of victims of school bullying were also victims of cyberbullying. Girls were twice as likely as boys to be victims of cyberbullying $(22.4 \%$ vs. $10.9 \% ; p<.001)$ and both forms of bullying (13.5\% vs. $6.8 \% ; p<.001)$. Students who were in lower grades were more likely to be victims of school bullying, whereas those in higher grades were more likely to be victims of cyberbullying or both forms of bullying victimization. 
Fig. 1. Prevalence of bullying victimization by gender.

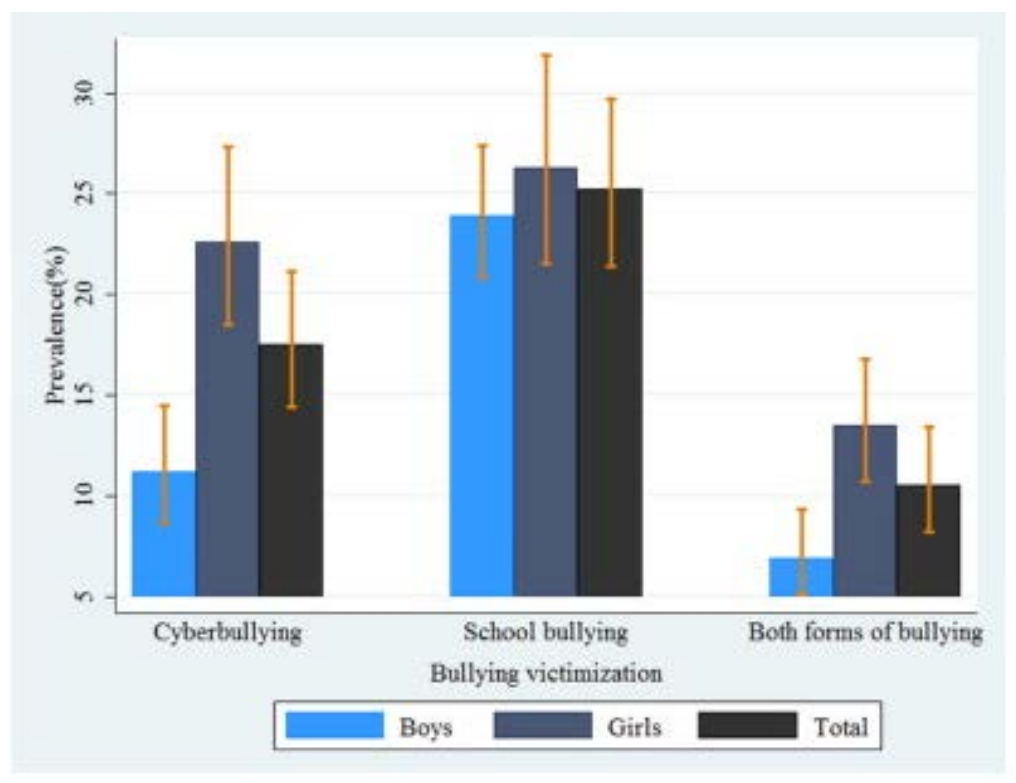

\section{Association between bullying victimization and breakfast skipping}

Table 3 presents associations between bullying victimization with breakfast skipping using multinomial logistic regression analyses. Victims of both cyberbullying and school bullying presented greater likelihood of often breakfast skipping ( $R R=1.80 ; 95 \% \mathrm{Cl}=1.33-2.43$ ) and frequent breakfast skipping ( $\mathrm{RR}=2.66 ; 95 \% \mathrm{Cl}=1.76-4.04)$. Results were similar when adjusting for grade, gender, body weight perception, and tobacco and alcohol use, as victims of both cyberbullying and school bullying presented greater likelihood of often breakfast skipping ( $R R=1.55 ; 95 \%$ $\mathrm{Cl}=1.17-2.06)$ and frequent breakfast skipping $(\mathrm{RR}=1.97 ; 95 \% \mathrm{Cl}=1.28-3.03)$. There were also significant associations between either form of bullying alone and breakfast skipping.

Table 3. Associations of cyberbullying and school bullying victimization with breakfast skipping amongst schoolchildren.

$\begin{array}{llll}\text { Cyberbullying } & \text { Model } & \text { Often breakfast skipping } & \begin{array}{l}\text { Frequent breakfast } \\ \text { skipping }\end{array} \\ & 1 & 1.66(1.43-1.94)^{* * *} & 2.53(1.75-3.66)^{* *} \\ & 2 & 1.57(1.40-1.76)^{* * *} & 2.27(1.61-3.21)^{* *} \\ \text { School bullying } & 3 & 1.44(1.33-1.55)^{* * *} & 1.90(1.37-2.64)^{* *} \\ & 1 & 1.23(1.02-1.47)^{*} & 1.43(1.26-1.63)^{* *} \\ \text { Both forms of bullying } & 2 & 1.25(1.06-1.48)^{*} & 1.48(1.26-1.72)^{* *} \\ & 3 & 1.18(1.00-1.39) & 1.28(1.08-1.53)^{*} \\ & 1 & 1.80(1.33-2.43)^{* *} & \\ & 2 & 1.71(1.28-2.28)^{* *} & 2.66(1.76-4.04)^{* *} \\ & 3 & 1.55(1.17-2.06)^{*} & 1.92(1.57-3.71)^{* *} \\ & & & \end{array}$

Note: Results shown as Relative Risk Ratio (95\% confidence interval). Eat breakfast everyday was used as reference category.

Model 1: unadjusted.

Model 2: adjusted for grade and gender.

Model 3: adjusted for grade, gender, educational level of father, educational level of mother, body weight perception, and tobacco and alcohol use.

$* p<.05 ; * * p .01 ; * * * p<.001$.

a Eating breakfast three times or more per week.

b Eating breakfast two times or less per week. 


\section{Mediation analysis}

Often breakfast skipping was not significantly associated with depression (Path B) while controlling for school bullying ( $B=.22, t=1.50, p=.194)$, cyberbullying $(B=.20, t=1.36, p=.233)$, and both forms of bullying ( $B=.20$, $t=1.43, p=.212$ ), and therefore did not meet criteria necessary to test for mediation. With respect to frequent breakfast skipping, criteria for steps 1, 2 and 3 were all met ( Fig. 2); however, step 4 criteria differed by type of bullying victimization. Depression fully mediated the association between school bullying victimization and frequent breakfast skipping as the latter was reduced to non-significant when controlling for depression ( Fig. 2a). Depression partially mediated the association between both cyberbullying victimization and being a victim of both types of bullying with frequent breakfast skipping ( Fig. $2 \mathrm{~b}$ and c). Sobel tests confirmed the partial meditational relationships of frequent breakfast skipping with cyberbullying $(z=6.50, p<.001)$ and both types of bullying $(z=6.37, p<.001)$.

Fig. 2. Results of the mediational analyses on the relationship between bullying victimization and breakfast skipping.

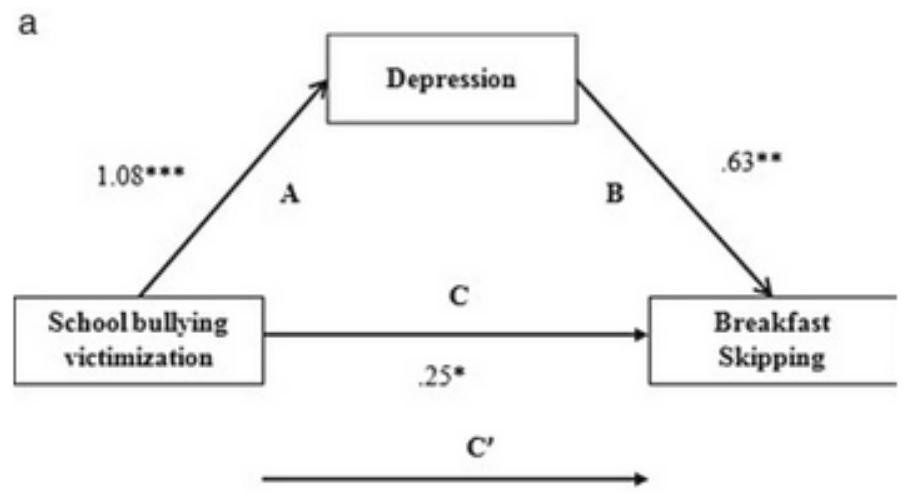

.13

b
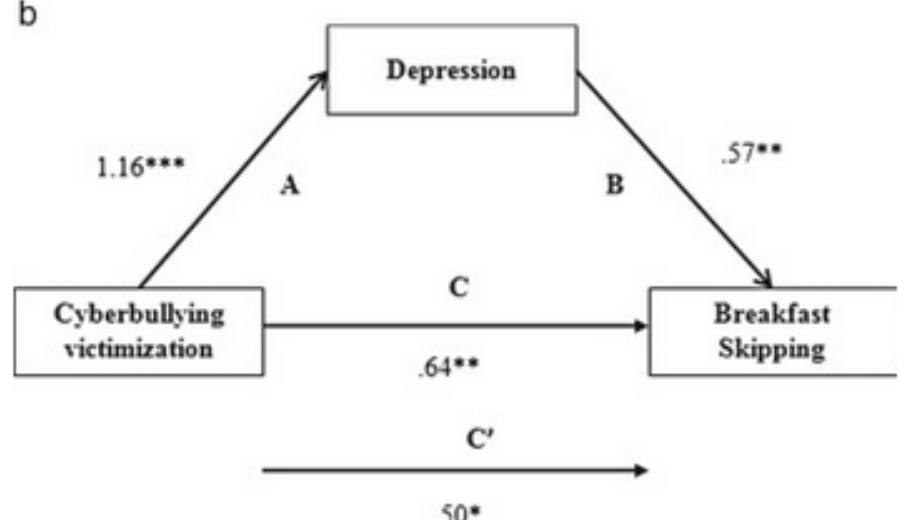

$.50^{*}$

C
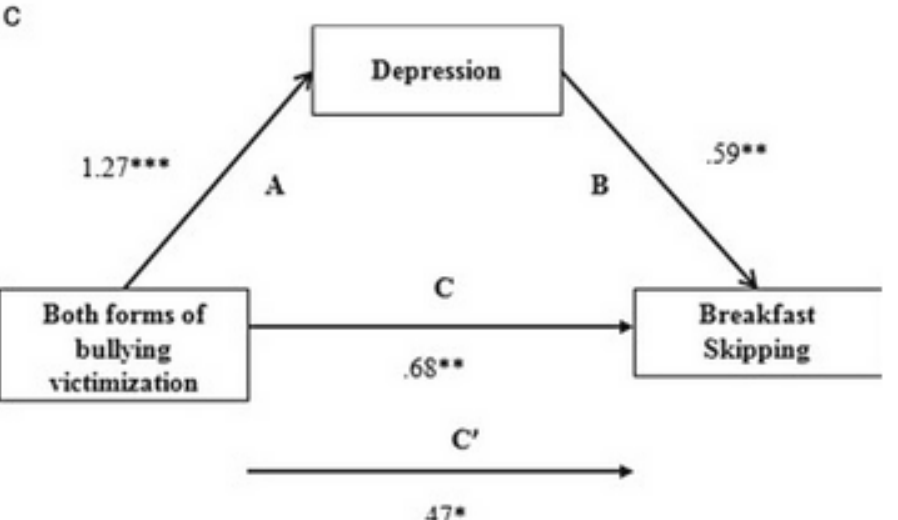

Note: Binary (a) and multinomial ( $b$ and c) logistic regression were performed, all models controlling for grade, gender, body weight perception, and tobacco and alcohol use; $b$ and $c$ analyses compared "seldom breakfast skipping vs. eat breakfast everyday" and "frequent breakfast skipping vs. eat breakfast everyday," but only the latter group of comparison met criteria necessary to test for mediation, and is therefore presented; Sobel test evaluating the indirect effect of bullying victimization on frequent breakfast skipping through depression was significant for cyberbullying $(z=6.29, p<.001)$ and both types of bullying $(z=6.31, p<.001)$. Coefficient level of significance: ${ }^{*} p<.05$; $* * p<.01 ; * * p<.001$. 


\section{Discussion}

This is the first study to provide evidence of troubling relationships between cyberbullying, school bullying, and breakfast skipping. Even after controlling for demographics characteristics, SES and selected health risk behaviours, the results suggest that the increased vulnerability of victims of both cyberbullying and school based bullying may negatively impede breakfast consumption and that symptoms of depression appear to mediate these relationships.

These results support and extend previous studies implicating not just the experience of traditional bullying but also that of cyberbullying on the development of unhealthy eating behaviours (Farrow, Fox, 2011, Kaltiala-Heino et al, 2000 and Libbey et al, 2008). However, unlike a recent study which failed to establish emotional symptoms (anxiety and depression) as mediators of the associations between bullying and restrained eating (Farrow \& Fox, 2011), the current study identified a full mediating role for depression in the paths between bullying victimization and frequent breakfast skipping. These differences may reflect the use of different outcome variables to assess eating (breakfast skipping vs. restrained eating). Indeed, restrained eating may be more complex than breakfast skipping behaviour; reflecting a constellation of behaviours and attitudes (Polivy \& Herman, 2005). For this study the findings suggest that victims of bullying may endure episodes of depression, and in turn, develop a tendency to miss consumption of breakfast. The partial mediating role of depression on the association between cyberbullying and breakfast skipping, however, implies that other factors may also act as mediators in these etiological relationships.

The possible mechanism mediating these associations could rely on the dysregulation of appetite due to a psychological imbalance. Given the fact that bullying carries intense emotional, social and psychological distress, victims may often have no appetite and thus will tend to skip breakfast (Polivy \& Herman, 2005). A school easily becomes a frightening, unhappy and unsafe place for victims of school bullying (Boulton \& Underwood, 1992). Victims may wake up in the morning feeling completely anxious or panicked and such fear and anxiety may undermine their appetite, resulting in breakfast skipping.

We cannot rule out the alternative mechanism given the cross-sectional design of this study. According to the theoretical approach developed by Finkelhor and Asdigian (1996), risk behaviours may place some youths at increased risk for victimization as they may increase the potential victim's target vulnerability (e.g., physical weakness and psychological distress). Indeed, breakfast skipping may affect students' mood and psychological wellbeing (Polivy \& Herman, 2005), thus making them perfect targets for bullies. Future research with longitudinal data will be important for establishing temporal ordering of these relationships.

This study not only provides evidence of the association between bullying victimization and breakfast skipping but also addresses the need to identify and support victims of bullying. Since cyberbullying and school bullying victimization may have negative effects on breakfast consumption, they could be seen as risk factors for breakfast skipping. As such, interventions that effectively reduce cyberbullying and school bullying victimization may potentially reduce, at least in part, the prevalence of breakfast skipping amongst youths. Overall, the prevalence of cyberbullying and school bullying victimization reported herein is relatively lower than documented in other studies published in Canada (Beran, Qing, 2007, Li, 2006 and Mishna et al, 2010). This discrepancy might be partially explained either by the fact that we may have missed some bullying victims because of differential non-response or by the use of differing questionnaires, methodologies and age groups. However, the prevalence and overlap of cyberbullying and school bullying victimization documented in the current study are comparable with those of a recent American study that has used similar items from the CDC YRBS to measure cyberbullying and school bullying victimization amongst high school students (Schneider et al., 2012). These findings justify the need for interventions that address both forms of victimization. Our results showed that students who were in lower grades were more likely to be victims of school bullying, whereas those in higher grades were more likely to be victims of cyberbullying or both forms of bullying victimization. This may be explained by the relatively limited access to cell phones and Internet or social networking sites for younger children. 
Many researchers have focused on breakfast skipping in the last few decades, but they have used different definitions and timeframes to assess breakfast skipping (Holtzman, 2010), which may complicate the comparison of the prevalence across studies. Moreover, eating habits vary greatly in different countries and cultures. The prevalence of breakfast skipping (50.2\%) documented in this study is substantial, and justifies the need for intervention programmes intended to increase breakfast consumption amongst children. Results have shown that breakfast skipping is more common amongst girls and increases with age (Vereecken et al., 2009). The fact that older students skip breakfast more often than younger students is not surprising. As they are growing, children become less influenced by their parents. This fact has been well documented by an American school-based study that focused on breakfast habits at the age of 11 vs. 16-18 (Terre, Drabman, \& Meydrech, 1990).

The current study has also revealed that participants who considered themselves overweight are more likely to never or almost never eat breakfast. These results corroborate previous findings indicating that breakfast skipping might be considered a weight control strategy amongst people who are overweight or obese (Shaw, 1998). Although controversial, evidence has shown that breakfast skipping behaviour is associated with obesity and overweight (Niemeier et al, 2006, Rampersaud et al, 2005 and Timlin et al, 2008). Nevertheless, even after controlling for body weight perception, the results of this study indicate that bullying victimization may predict reduced breakfast consumption.

This study has several limitations that need to be considered. First, the low overall response rates (42\%) to the survey limit the generalizability of the findings. Second, students who were in lower grades were oversampled, and the survey did not capture students who had a spare period, who were absent from school or dropped out of school. Since evidence shows that students in higher grades and those who drop out of school are at greater risk of engaging in health-risk behaviours (Brener \& Collins, 1998), the prevalence and association between bullying victimization and breakfast skipping reported herein may be underestimated especially amongst older students given their numerical underrepresentation and their increased likelihood of dropping out of school. Third, the cross-sectional nature of the data precludes evaluation of temporality and causality of the observed relationship between bullying victimization and breakfast skipping. Another limitation of our study concerns the reliability of the data gathered. Indeed, despite demonstrated test-retest reliability of the YRBS amongst students from across these grades (Zullig, Pun, Patton, \& Ubbes, 2006), potential reliability issues might be associated with the use of single-item measures and self-reporting data from these age groups. Finally, there were no questions in the survey addressing the frequency or intensity of bullying victimization. The latter would have helped to explore potential patterns within the association between bullying victimization and breakfast skipping with respect to the severity of both components.

Despite these limitations, the current study adds unique implications to the literature, indicating an association between breakfast skipping with cyberbullying and school bullying victimization even after adjusting for underlying characteristics. Experiences of bullying victimization and depression may be important points of focus for breakfast skipping prevention efforts. Targeting those at particularly high risk may increase the effectiveness of interventions as well as reduce poor eating habits subsequent to bullying victimization. There is a crucial need for service providers to be informed about the experiences youths are likely facing. On the other hand, breakfast skipping can be considered a potential warning sign of cyberbullying and school bullying victimization. Increasing awareness may help parents to more closely monitor their children so that the sooner they notice breakfast skipping the earlier they can investigate and support their children. Experiences of depression and breakfast skipping may be for some the first steps from being bullied to developing more disordered eating behaviours. Further research using longitudinal data and a more representative sample is necessary to confirm these results and to clarify the underlying mechanisms. 


\section{References}

R.M. Baron, D.A. Kenny

The moderator-mediator variable distinction in social psychological research. Conceptual, strategic, and statistical considerations Journal of Personality and Social Psychology, 51 (6) (1986), pp. 1173-1182

\section{T. Beran, L. Qing}

The relationship between cyberbullying and school bullying

Journal of Student Wellbeing, 1 (2) (2007), pp. 15-33

C.S. Berkey, H.R. Rockett, M.W. Gillman, A.E. Field, G.A. Colditz

Longitudinal study of skipping breakfast and weight change in adolescents

International Journal of Obesity and Related Metabolic Disorders: Journal of the International Association for the Study of Obesity, 27 (10)

(2003), pp. 1258-1266 http://dx.doi.org/10.1038/sj.ijo.08024020802402 [pii]

M.J. Boulton, K. Underwood

Bully/victim problems among middle school children

The British Journal of Educational Psychology, 62 (Pt. 1) (1992), pp. 73-87

\section{T. Breguet}

Frequently asked questions about cyberbullying

Rosen Publishing Group, Inc, New York (2007)

\section{N.D. Brener, J.L. Collins}

Co-occurrence of health-risk behaviors among adolescents in the United States

The Journal of Adolescent Health, 22 (3) (1998), pp. 209-213 http://dx.doi.org/10.1016/S1054-139X(97)00161-4 S1054-139X(97)00161-4 [pii]

Centers for Disease Control and Prevention

Youth risk behavior survey. Questionnaires \& item rationales

Available fromhttp://www.cdc.gov/HealthyYouth/yrbs/questionnaire_rationale.htm (2009) Accessed 13.08 .05

Centre for Addiction and Mental Health

Ontario student drug use and health survey

Available fromhttp://www.camh.ca/en/research/news_and_publications/ontario-student-drug-use-and-health-survey/ (2009) Accessed 13.12 .09

\section{C.V. Farrow, C.L. Fox}

Gender differences in the relationships between bullying at school and unhealthy eating and shape-related attitudes and behaviours The British Journal of Educational Psychology, 81 (Pt. 3) (2011), pp. 409-420 http://dx.doi.org/10.1348/000709910X525804

F. Fernandez-Aranda, I. Krug, R. Granero, J.M. Ramon, A. Badia, L. Gimenez

Individual and family eating patterns during childhood and early adolescence. An analysis of associated eating disorder factors

Appetite, 49 (2) (2007), pp. 476-485 http://dx.doi.org/10.1016/j.appet.2007.03.004 S0195-6663(07)00043-8 [pii]

\section{Finkelhor, N.L. Asdigian}

Risk factors for youth victimization. Beyond a lifestyles/routine activities theory approach

Violence and Victims, 11 (1) (1996), pp. 3-19

R.O. Frost, G.A. Goolkasian, R.J. Ely, F.A. Blanchard

Depression, restraint and eating behavior

Behaviour Research and Therapy, 20 (2) (1982), pp. 113-121 0005-7967(82)90111-5; [pii]

N.G. Guerra, K.R. Williams, S. Sadek

Understanding bullying and victimization during childhood and adolescence. A mixed methods study

Child Development, 82 (1) (2011), pp. 295-310 http://dx.doi.org/10.1111/j.1467-8624.2010.01556.x

\section{D.S. Hawker, M.J. Boulton}

Twenty years' research on peer victimization and psychosocial maladjustment. A meta-analytic review of cross-sectional studies Journal of Child Psychology and Psychiatry, and Allied Disciplines, 41 (4) (2000), pp. 441-455 
C. Hay, R. Meldrum

Bullying victimization and adolescent self-harm. Testing hypotheses from general strain theory

Journal of Youth and Adolescence, 39 (5) (2010), pp. 446-459 http://dx.doi.org/10.1007/s10964-009-9502-0

S. Hinduja, J.W. Patchin

Bullying beyond the schoolyard. Preventing and responding to cyberbullying

Corwin Press, Thousand Oaks, CA (2009)

\section{N.S. Holtzman}

To skip or not to skip? Varying definitions of breakfast skipping and associations with disordered eating, obesity, and depression BCh thesis, Wesleyan University(2010)

R.E. Isralowitz, N. Trostler

Substance use. Toward an understanding of its relation to nutrition-related attitudes and behavior among Israeli high school youth The Journal of Adolescent Health, 19 (3) (1996), pp. 184-189 http://dx.doi.org/10.1016/S1054-139X(96)00081-X

J. Juvonen, E.F. Gross

Extending the school grounds? Bullying experiences in cyberspace

The Journal of School Health, 78 (9) (2008), pp. 496-505 http://dx.doi.org/10.1111/j.1746-1561.2008.00335.x JOSH335 [pii]

R. Kaltiala-Heino, M. Rimpela, P. Rantanen, A. Rimpela

Bullying at school. An indicator of adolescents at risk for mental disorders

Journal of Adolescence, 23 (6) (2000), pp. 661-674 http://dx.doi.org/10.1006/jado.2000.0351S0140-1971(00)90351-8 [pii]

A. Keski-Rahkonen, J. Kaprio, A. Rissanen, M. Virkkunen, R.J. Rose

Breakfast skipping and health-compromising behaviors in adolescents and adults

European Journal of Clinical Nutrition, 57 (7) (2003), pp. 842-853 http://dx.doi.org/10.1038/sj.ejcn.1601618

R.S. Lazarus

Coping theory and research. Past, present, and future

Psychosomatic Medicine, 55 (3) (1993), pp. 234-247

K.A. Levin, J. Kirby, C. Currie

Family structure and breakfast consumption of 11-15 year old boys and girls in Scotland, 1994-2010. A repeated cross-sectional study BMC Public Health, 12 (228) (2012) http://dx.doi.org/10.1186/1471-2458-12-228 1471-2458-12-228 [pii]

Q. Li

Cyberbullying in schools. A research of gender differences

School Psychology International, 27 (2) (2006), pp. 157-170

H.P. Libbey, M.T. Story, D.R. Neumark-Sztainer, K.N. Boutelle

Teasing, disordered eating behaviors, and psychological morbidities among overweight adolescents

Obesity (Silver Spring, Md.), 16 (Suppl. 2) (2008), pp. S24-S29 http://dx.doi.org/10.1038/oby.2008.455 oby2008455 [pii]

L. Lien

Is breakfast consumption related to mental distress and academic performance in adolescents?

Public Health Nutrition, 10 (4) (2007), pp. 422-428

K.K. Melve, A. Baerheim

Signs of subclinical eating disorders in teenage girls

Scandinavian Journal of Primary Health Care, 12 (3) (1994), pp. 197-203

F. Mishna, C. Cook, T. Gadalla, J. Daciuk, S. Solomon

Cyber bullying behaviors among middle and high school students

The American Journal of Orthopsychiatry, 80 (3) (2010), pp. 362-374 http://dx.doi.org/10.1111/j.1939-0025.2010.01040.x

H.M. Niemeier, H.A. Raynor, E.E. Lloyd-Richardson, M.L. Rogers, R.R. Wing

Fast food consumption and breakfast skipping. Predictors of weight gain from adolescence to adulthood in a nationally representative sample The Journal of Adolescent Health, 39 (6) (2006), pp. 842-849 http://dx.doi.org/10.1016/j.jadohealth.2006.07.001 S1054-139X(06)00264-3 [pii] 
J.A. O'Dea, P. Caputi

Association between socioeconomic status, weight, age and gender, and the body image and weight control practices of 6- to 19-year-old children and adolescents

Health Education Research, 16 (5) (2001), pp. 521-532

D. Olweus

Bullying at school. What we know and what we can do

Blackwell Publishing, Cambridge, MA (1993)

J.W. Patchin, S. Hinduja

Cyberbullying and self-esteem

The Journal of School Health, 80 (12) (2010), pp. 614-621 http://dx.doi.org/10.1111/j.1746-1561.2010.00548.x

S. Perren, J. Dooley, T. Shaw, D. Cross

Bullying in school and cyberspace. Associations with depressive symptoms in Swiss and Australian adolescents

Child and Adolescent Psychiatry and Mental Health, 4 (2010), p. 28 http://dx.doi.org/10.1186/1753-2000-4-28

J. Polivy, C.P. Herman

Mental health and eating behaviours. A bi-directional relation

Canadian Journal of Public Health, 96 (Suppl. 3) (2005), pp. S43-S46

G.C. Rampersaud, M.A. Pereira, B.L. Girard, J. Adams, J.D. Metzl

Breakfast habits, nutritional status, body weight, and academic performance in children and adolescents

Journal of the American Dietetic Association, 105 (5) (2005), pp. $743-760$ http://dx.doi.org/10.1016/j.jada.2005.02.007 S0002822305001513

[pii]

S.K. Schneider, L. O'Donnell, A. Stueve, R.W. Coulter

Cyberbullying, school bullying, and psychological distress. A regional census of high school students

American Journal of Public Health, 102 (1) (2012), pp. 171-177 http://dx.doi.org/10.2105/AJPH.2011.300308

M.E. Shaw

Adolescent breakfast skipping. An Australian study

Adolescence, 33 (132) (1998), pp. 851-861

A.M. Siega-Riz, B.M. Popkin, T. Carson

Trends in breakfast consumption for children in the United States from 1965-1991

The American Journal of Clinical Nutrition, 67 (4) (1998), pp. 748S-756S

M.E. Sobel

Asymptotic confidence intervals for indirect effects in structural equation models

Sociological Methodology, 13 (1982), pp. 290-312

K.E. Storey, R.M. Hanning, I.A. Lambraki, P. Driezen, S.N. Fraser, L.J. McCargar

Determinants of diet quality among Canadian adolescents

Canadian Journal of Dietetic Practice and Research: A Publication of Dietitians of Canada, 70 (2) (2009), pp. 58-65

L. Terre, R.S. Drabman, E.F. Meydrech

Relationships among children's health-related behaviors. A multivariate, developmental perspective

Preventive Medicine, 19 (2) (1990), pp. 134-146

M.T. Timlin, M.A. Pereira, M. Story, D. Neumark-Sztainer

Breakfast eating and weight change in a 5 -year prospective analysis of adolescents. Project EAT (Eating Among Teens)

Pediatrics, 121 (3) (2008), pp. e638-e645 http://dx.doi.org/10.1542/peds.2007-1035 121/3/e638 [pii]

C. Vereecken, M. Dupuy, M. Rasmussen, C. Kelly, T.R. Nansel, H. Al Sabbah

Breakfast consumption and its socio-demographic and lifestyle correlates in schoolchildren in 41 countries participating in the HBSC study International Journal of Public Health, 54 (Suppl. 2) (2009), pp. S180-S190 http://dx.doi.org/10.1007/s00038-009-5409-5 
Body Image, 5 (4) (2008), pp. 404-408 http://dx.doi.org/10.1016/j.bodyim.2008.04.006 S1740-1445(08)00055-7 [pii]

M.L. Ybarra, K.J. Mitchell, J. Wolak, D. Finkelhor

Examining characteristics and associated distress related to Internet harassment. Findings from the Second Youth Internet Safety Survey Pediatrics, 118 (4) (2006), pp. E1169-E1177 http://dx.doi.org/10.1542/peds.2006-0815 118/4/e1169 [pii]

K.J. Zullig, S. Pun, J.M. Patton, V.A. Ubbes

Reliability of the 2005 middle school Youth Risk Behavior Survey

The Journal of Adolescent Health, 39 (6) (2006), pp. 856-860 http://dx.doi.org/10.1016/j.jadohealth.2006.07.008 S1054-139X(06)00269-2 [pii] 